

\title{
Avaliação de eficiência da implantação da técnica de bioengenharia de solos de enrocamento vegetado
}

Guilherme Matos Antônio ${ }^{1}$, Francisco Sandro Rodrigues Holanda ${ }^{2}$, Luiz Diego Vidal Santos ${ }^{3}$, Bruno de Santana Mendonça $^{4}$, Rayssa Juliane Souza de Jesus ${ }^{5}$, Priscila Angel de Oliveira Silva ${ }^{5}$

${ }^{1}$ Ecólogo, UFS, Cidade Universitária Prof. José Aloisio de Campos; CEP: 49.100-000, São Cristóvão, SE, guilhermematos.antonio@gmail.com. ${ }^{2}$ Professor Titular, Universidade Federal de Sergipe-UFS, Cidade Universitária Prof. José Aloisio de Campos; CEP: 49.100-000, São Cristóvão, SE, fholanda@infonet.com.br (autor correspondente). ${ }^{3}$ Doutorando em Ciência da Propriedade Intelectual, UFS, Cidade Universitária Prof. José Aloisio de Campos; CEP: 49.100-000, São Cristóvão, SE, vidal.center@academico.ufs.br. ${ }^{4}$ Engenheiro Agrônomo, UFS, Cidade Universitária Prof. José Aloisio de Campos; CEP: 49.100-000, São Cristóvão, SE, brunoestudo8@ gmail.com. . ${ }^{5}$ Estudante Engenharia Florestal, UFS, Cidade Universitária Prof. José Aloisio de Campos; CEP: 49.100-000, São Cristóvão, SE, rayssajs@icloud.com, priscila aos@outlook.com.

Artigo recebido em 01/03/2021 e aceito em 29/07/2021

\section{R E S UM O}

O Baixo São Francisco está em constante dinâmica hidroambiental resultante das alterações promovidas na calha do rio, representadas pelos processos geomorfológicos naturais ou por ações antrópicas como a construção das barragens que por sua vez acelerou as mudanças geomorfológicas resultando em processos erosivos crescentes nas suas margens. O objetivo deste trabalho foi avaliar a implantação de técnicas de recuperação hidroambiental com uso de bioengenharia de solos na margem do rio São Francisco. A área estudada compreende um trecho do baixo curso do rio São Francisco, localizado no município de Amparo do São Francisco, no estado de Sergipe, nordeste do Brasil, onde técnicas de bioengenharia de solos, como enrocamento vegetado, foi implementada no ano de 2011. Três grupos de indicadores individuais foram selecionados e que contribuíram para a avaliação de Recuperação da Área Degradada relacionados à qualidade do solo, como resistência do solo à penetração e Velocidade de Infiltração Básica, e também à recuperação da biodiversidade como banco de sementes e a regeneração natural da área por meio de indicadores como composição e cobertura linear de espécies. A metodologia empregada contempla uma avaliação dos resultados originados do uso da biotécnica a partir da identificação da contribuição da vegetação que auxilia na contenção de taludes, uma vez que a cobertura vegetal protege a superfície do solo contra eventos erosivos promovidos pelo vento e a água da chuva. O reforço mecânico trazido pelo sistema radicular das plantas contra cisalhamento do solo se apresentou por meio da menor resistência à penetração do solo e maior Taxa de infiltração.

Palavras-chave: Recuperação de áreas degradadas, Erosão, Rio São Francisco.

\section{Evaluation of efficiency of the implementation of soil bioengineering technique}

\section{A B S T R A C T}

The Lower São Francisco is in constant hydro-environmental dynamics resulting from the changes promoted in the river channel, represented by geomorphological processes or by anthropic actions such as the construction of dams that in turn caused geomorphological changes resulting in the acceleration of erosive processes on its banks. The objective of this work was to evaluate the implementation of hydroenvironmental recovery techniques using soil bioengineering on the bank of the São Francisco River. The studied area comprises a stretch of the low course of the São Francisco River, located in the municipality of Amparo do São Francisco, in the state of Sergipe, northeastearn Brazil, where soil bioengineering technique, such as vegetated rockfill, was implemented in 2011. Three groups of individual indicators were selected that together contributed to the assessment of Degraded Area Recovery related to soil quality, such as soil resistance to penetration and Basic Infiltration Speed, to the recovery of biodiversity as a seed bank and the natural area regeneration through indicators such as composition and linear species coverage. The employed methodology includes an evaluation of the results from the use of biotechnology based on the identification of the vegetation contribution that helps to contain slopes, since the vegetation cover protects the soil surface against erosive actions such as wind and rainwater. The mechanical reinforcement brought 
by the root system against soil shear was shown by the lower resistance to soil penetration and a higher infiltration rate.

Keywords: Degraded Areas Recovery, erosion, São Francisco River.

\section{Introdução}

Último trecho da Bacia Hidrográfica do Rio São Francisco, alcançando parte do território dos estados de Pernambuco, Bahia, Sergipe e Alagoas, o Baixo São Francisco (BSF), repercute alterações hidroambientais provocadas por ações antrópicas à sua montante, com os seus recursos hídricos se prestando a múltiplos usos como geração de energia, abastecimento humano, dessedentação animal, navegação, pesca e irrigação (Soares et al., 2019). A construção de barragens na calha de rio, tem gerado impactos ambientais como perda de rotas de migração de espécies aquáticas, desmatamento da vegetação ripária, além de realocação de população ribeirinha com perda de sítios arqueológicos e culturais (Arthur et al., 2020; Campos et al., 2020). É também reportado a cada vez mais frequente exposição das margens dos rios sem a proteção adequada da mata ciliar proporcionando uma exposição do solo, facilitando a atuação de processos erosivos, diminuição de depósitos de sedimentos gerando perdas de solo e sedimentação do canal do rio (Hilary et al., 2021; Zhang et al., 2020).

A vulnerabilidade dos taludes marginais pode ser também explicada pela baixa coesão do solo, que desmatado ficam ainda mais vulneráveis aos processos erosivos. A textura predominante dos Neossolos Flúvivos dos taludes no BSF é geralmente arenosa, principalmente nas camadas mais profundas, trazendo maior suscetibilidade à erosão (Moura et al., 2017). Essas camadas apresentam agregados com baixa estabilidade, tornando-os mais susceptíveis ao cisalhamento, levando à intensificação dos processos erosivos potencializados pelo fluxo e refluxo de ondas, resultado do desprendimento de blocos de solo (Holanda et al., 2011; Araújo Filho et al., 2017; Gu et al., 2020; Parhizkar et al,. 2021).

Mesmo considerando que a erosão marginal do BSF é também um processo natural resultante da dinâmica geomorfológica daquele ambiente, são necessárias ações para promoção da sua recuperação hidroambiental (Santana et al., 2012). Muitas dessas ações visam a proteção das margens do rio, com uso de vegetação nativa de rápido desenvolvimento, $\mathrm{e}$ adaptada à dinâmica hidrológica, que possa também promover a redução dos movimentos de massa, sujeitos às constantes alterações na cota do rio São Francisco, de vazão regularizada pela operação das barragens (Holanda et al., 2020).

Mesmo sendo geradoras de grandes impactos ambientais, as hidrelétricas desempenham um papel de destaque na matriz energética do mundo, aumentando a segurança energética e reduzindo os custos a curto prazo para o usuário final (Hara et al., 2020). Buscando mitigar os impactos ambientais resultantes da instalação das hidrelétricas nas margens dos rios, trabalhos de recuperação hidroambiental são conduzidos por meio da bioengenharia de solos (Rey et al., 2019).

As principais recomendações para o uso da bioengenharia de solos consistem em proteger o solo contra os diversos tipos de erosão recuperando a melhor capacidade ecossistêmica de armazenamento de matéria e energia (Rosa \& Gaiofatto, 2019), melhoria das condições físicas e microbiológicas do solo pelas raízes das plantas, equilíbrio microclimático próximo ao solo e integração da estrutura na paisagem (Vázquez et al., 2020), apresentando vantagens econômicas, como menores custos de construção, manutenção e reabilitação (Maffra e Sutili, 2020). No entanto, deve-se conhecer as características técnicas das variáveis que atuam nesse processo como as contribuições da vegetação na estabilização do solo e no controle do processo erosivo (EmadiTaftiet al., 2021. Carvalho et al., 2020). Muitos autores ao avaliarem a contribuição do sistema radicular de gramíneas na estabilização de um talude, demonstraram que raízes densas e 
fibrosas contribuem para melhor resistência do solo, estabilização do talude com interceptação da água da chuva e infiltração (Irving et al., 2018; Xu \& Pittock, 2019; Jiang et al., 2020).

Para Sutili et al. (2018), os modelos de intervenção recomendados para esses tipos de obras podem ser adaptados a diferentes realidades regionais tanto no uso de equipamentos como também na utilização técnica com espécies previamente estudadas quanto às suas características biotécnicas. $\mathrm{O}$ grande desafio deste tipo de projeto é definir que variáveis devem ser monitoradas uma vez que diferentes tipos de restauração natural requerem a análise de diferentes dados matriciais (Koppa et al., 2019). Partindo-se da hipótese de que a recuperação hidroambiental se fará eficiente se orientada por metodologias testadas e que possam interpretar a sua eficiência na recomposição da qualidade ambiental, este trabalho tem por objetivo, avaliar a implantação de técnicas de recuperação hidroambiental com uso de bioengenharia de solos na margem do rio São Francisco.

As seções seguintes deste artigo estão organizadas da seguinte forma: A primeira Seção apresenta a metodologia aplicada no projeto proposto, a segunda seção descreve os resultados da coleta de dados, assim como a discussão sobre as informações coletadas, e finalizando com as conclusões.

\section{Material e métodos}

Para a realização do estudo foi selecionada uma área onde foram implantadas técnicas de bioengenharia de solos no ano de 2011, em talude com $80 \mathrm{~m}$ de comprimento, e inclinação de $27^{\circ} \mathrm{em}$ um trecho do Baixo São Francisco, localizado no município de Amparo do São Francisco, no estado de Sergipe (coordenadas UTM $N=8.868 .789,506$ e $E=736.583,864)$, (Figura 1).

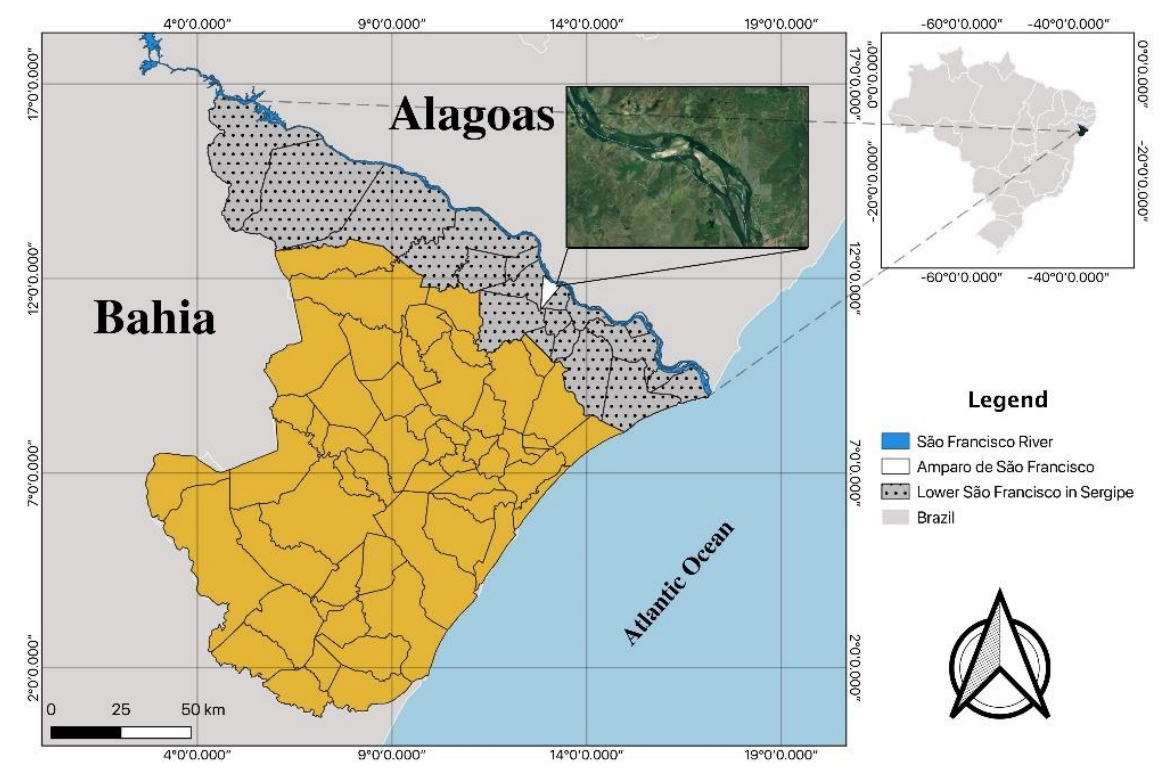

Figura 1. Mapa de localização da área de estudo em Amparo de São Francisco, Sergipe. Fonte: Machado et al. (2018).

O clima da área estudada, segundo a classificação de Köppen, é do tipo Am, com temperatura média anual de $25^{\circ} \mathrm{C}$ apresentando chuvas no período do inverno, entre os meses de março e setembro com precipitação de 800 a $1.300 \mathrm{~mm}$. O solo é classificado como NEOSSOLO Flúvico, de acordo com a chave de classificação do Sistema 
Brasileiro de Classificação de Solos (Holanda, 2000). A textura do solo foi classificada como argilo-siltosa nas camadas superiores e nas camadas inferiores franco-arenosa. Essa granulometria distinta se deve ao tipo de solo uma vez que o seu processo de formação ocorre por meio da deposição de sedimentos aluviais de origem variada, ao longo do tempo sem uma relação pedogenética definida (Araujo Filho et al, 2017). A fração de areia nas camadas mais inferiores ocasiona uma maior quantidade de espaços vazios e fazendo com que as partículas fiquem mais distantes umas das outras, provocando redução na coesão do solo, o que gera agregados com baixa estabilidade $\mathrm{e}$ consequentemente uma maior erobilidade de solos em talude que sofrem frequentemente com processos erosivos (Moura et al., 2017).

$\mathrm{Na}$ área estudada foi implantada em 2011 a técnica de bioengenharia de solos denominada enrocamento vegetado, que consiste no uso de rochas de granulometria variada para proteção da base dos taludes. Em tempo, previamente à instalação dessa técnica, ocorreu o processo de retaludamento, em que o talude antes verticalizado, foi suavizado para o alcance da inclinação de $27^{\circ}$. O enroamento foi vegetado com estacas vivas das espécies que compõem a flora local como Aroeira (Schinus terebenthifolius Raddi) e Sabiá (Mimosa caesalpiniaefolia Benth), associadas ao uso de geotêxteis. No topo do talude foram utilizados em toda a sua extensão, retentores de sedimentos (bermalongas) confeccionados com malha de polipropileno fotodegradável, em formatos cilíndricos, com 2 metros de comprimento, preenchidos com fibra de coco (Cocos nucifera L.) que impediram que os sedimentos resultantes de deflúvio superficial ocorrido à montante, drenassem em forma de enxurrada talude a baixo, assim contribuindo para maior eficiência da técnica na estabilização do solo (Figura 2).

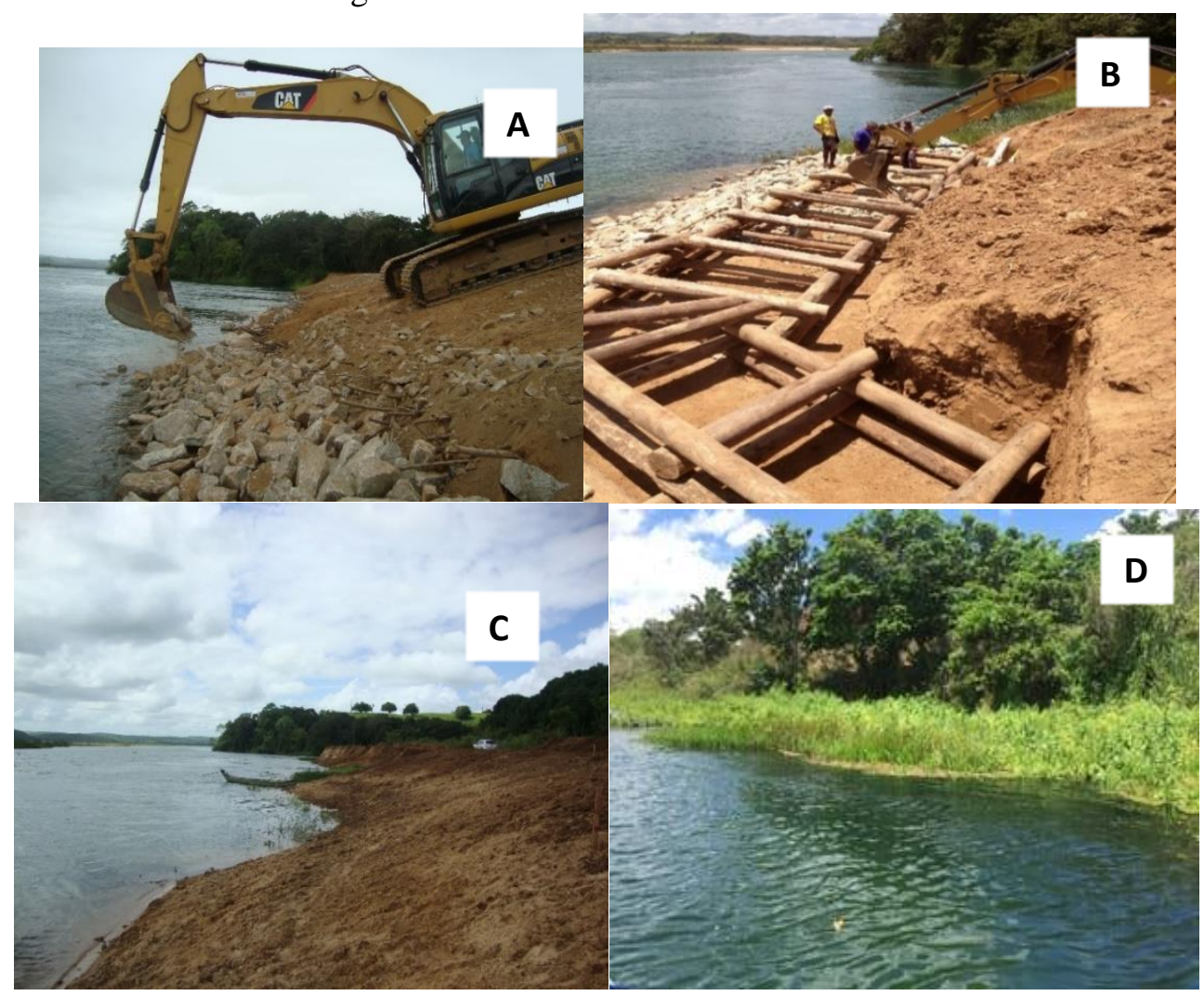

Figura 2. Evolução da implementação do enrocamento vegetado no período de 2011 a 2019. A Realização de enrocamento na base do talude; B - Fixação de estacas vivas de sabiá e aroeira; C Talude em processo de sucessão ecológica; D - Talude com cobertura vegetal em 2019. Fonte: LAB

Coleta de dados 
A principal finalidade de uma avaliação de Projeto de Recuperação de Áreas Degradadas (PRAD) é verificar se os objetivos iniciais do projeto foram atingidos de acordo com o próprio planejamento para que possa ser implementada a recuperação de forma efetiva e que seja economicamente viável (Almeida et al., 2019). Nesse sentido, foram selecionados três conjuntos de indicadores que contribuíram para a avaliação da técnica de bioengenharia de solos implantada: Regeneração natural, que traz a influência da vegetação e seu sistema radicular para a estabilização do talude; Banco de sementes, que informa sobre renovação ecossistêmica e qualidade do solo que por sua vez é avaliada pelos parâmetros relacionados a qualidade física do solo.

\section{Regeneração Natural}

$\mathrm{Na}$ regeneração natural foi avaliado o estrato herbáceo através do método de interseção na linha (Canfield, 1941, 1950) para determinação da composição e da cobertura linear das espécies. O método consiste em traçar linhas sobre a vegetação a ser amostrada e anotar o comprimento que a linha é interceptada por uma espécie. Foram registrados a ocorrência e o comprimento na área que cada espécie ocupa na área ao longo das linhas amostradas.

As plantas foram coletadas independentemente de estarem com material reprodutivo, uma vez que isso ocorre em momentos distintos, na dependência das campanhas de campo planejadas. Na sequência, esse material foi levado para identificação por meio de comparação com materiais já existentes no Herbário ASE. A área total amostrada foi de 28,60 metros de comprimento abrangendo toda a extensão de implantação da técnica de enrocamento vegetado, sendo a linha passada a 2,65 $\mathrm{m}$ a partir da base do talude, de forma paralela ao canal do rio.

A partir dos dados florísticos coletados nas linhas, foi calculada a Taxa de Cobertura Linear (CL), que é a soma linear da extensão de uma espécie amostrada dividida pelo total de metros amostrados; a Taxa de Cobertura Relativa (CR), que é a soma linear da extensão de uma espécie amostrada dividida pelo total de metros amostrados com espécie; a Densidade Relativa (DR), que é o número de indivíduos de uma espécie amostrada dividido pelo número total de indivíduos amostrados e o Índice de Valor de Importância (IVI), que é a soma da taxa de cobertura relativa e da densidade relativa.

\section{Banco de Sementes}

Para reconhecimento do banco de
sementes na área recuperada com o
enrocamento vegetado foi lançada
aleatoriamente, uma moldura de $0,50 \mathrm{~m}$ x 0,50 $\mathrm{m}$ (totalizando $0,25 \mathrm{~m}^{-2}$ ) na parcela do talude (Figura 3). Nas áreas denominadas como Vegetação Cerrada (VC), composta por uma área com mata densa com predominante presença de espécies arbóreas e como Vegetação Menos Densa (VMD), com predominância de vegetação arbustiva, foram coletadas quatro amostras na superfície do solo, contendo um misto de serapilheira, solo, sementes, matéria orgânica, em uma profundidade de $5 \mathrm{~cm}$, sendo na sequência acondicionadas em sacos plásticos identificados (Weerasinghe et al., 2019). 

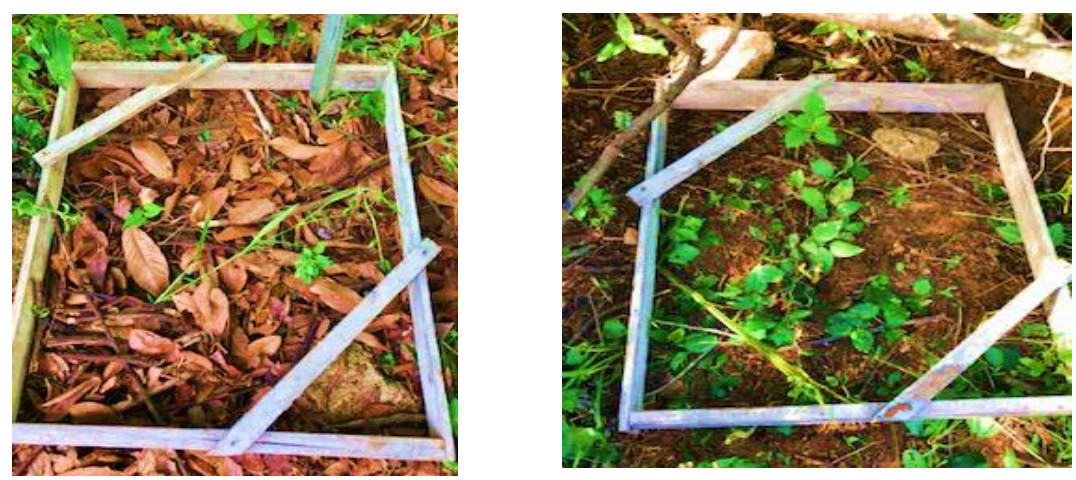

Figura 3. Coleta de material nas áreas de Vegetação Cerrada (VC) e Vegetação Menos Densa (VMD), para estudo do Banco de sementes.

Após a coleta do material, as amostras foram secas ao ar livre e em seguida peneiradas para retirada da serrapilheira. Foi realizado um teste de germinação em que foram retiradas quatro réplicas com $100 \mathrm{~g}$ de material para cada amostra e dispostas em caixas identificadas tipo GERBOX, de plástico. Logo após, foi adicionada água destilada para correção da umidade nas amostras, para trazer uniformidade para as mesmas. Desta maneira, foi possível observar a germinação de sementes, em condições iguais para todas as réplicas, permanecendo 2 semanas em um germinador de sementes tipo J-Prolab Mangelsdorf, com avaliações recorrentes nos dias 4, 7, 11 e 14 .

Foi avaliado o número de plântulas emergidas, a Velocidade de Germinação (VG), o tamanho das plântulas e, quando possível, a identificação botânica, visto que as plântulas emergidas foram retiradas da área amostral e levadas para casa de vegetação. A fim de verificar a taxa de germinação foi realizada também a contagem de sementes a cada $100 \mathrm{~g}$ de solo, para cada tratamento com 4 repetições.

\section{Atributos do Solo}

Foram avaliados como parâmetros para mensurar a qualidade física do solo as variáveis: Resistência à Penetração (RP) do solo e Velocidade Básica de Infiltração (VIB). Sendo RP avaliada por meio de penetrômetro de impacto (modelo IAA/ PLANALSUCAR STOLF), que consiste em registrar a contagem de batidas e a profundidade marcada que a haste penetra. Assim, foram coletados dados de três amostras com três repetições cada, em pontos aleatórios, mas ainda dentro da área de estudo e uma amostra controle fora da área estudada.

Os resultados obtidos em impactos $\mathrm{dm}^{-}$

${ }^{1}$ foram convertidos em resistência dinâmica por meio da fórmula seguinte (Stolf, 1983):

$$
R=5,6+6,89(N)
$$

Em que:



$N=$ Número de impactos do peso metálico.

Os resultados foram obtidos em $\mathrm{kgf} \mathrm{cm}^{-}$ 2 e depois transformados em MPa. Em conjunto, com auxílio de um trado holandês, foram retiradas amostras de solo para determinar a sua umidade de acordo com recomendações descritos no Manual de métodos de coleta e análise de solos (Teixeira et al., 2017). Os resultados de RP obtidos foram classificados de acordo com Soil Survey Staff (1993).

A coleta de dados sobre Velocidade de Infiltração Básica (VIB) no solo foi realizada por meio da metodologia proposta por Bernardo et al., (2008), que consiste em um infiltrômetro de anel, composto por dois anéis de diferentes diâmetros $(20$ e $40 \mathrm{~cm})$ e $15 \mathrm{~cm}$ de altura, instalados concentricamente ao solo para determinação das curvas de retenção. Assim, a partir dos dados coletados em campo foi possível determinar a VIB. Em tempo, a 
infiltração é o processo que a água penetra na superfície do solo e tem correlação direta com escoamento superficial, que integra os processos de erosão e inundação.

A lâmina de água que atravessa a superfície por unidade de tempo é a Velocidade de Infiltração Básica (VIB) (Silva et al., 2019). A infiltração do solo foi classificada de acordo com a adaptação dos parâmetros estabelecidos pelos autores citados.

Análises estatísticas

As três amostras com três repetições cada, em pontos aleatórios foram submetidos à análise de variância (ANOVA) e teste post hoc a fim de verificar diferenças significativas entre tratamentos. Os resultados foram analisados pelo software SPSS (SPSS Corp, 2017), e submetidos a análise de significância a 5\% de probabilidade.

\section{Resultados e discussão}

Regeneração Natural

$\mathrm{Na}$ avaliação da regeneração natural, considerou-se o registro de que foram trabalhadas na implantação do enrocamento vegetado somente as espécies aroeiras (Schinus terebenthifolius Raddi) e sabiá (Mimosa caesalpiniaefolia Benth). Passados 8 anos da implantação desta técnica de bioengenharia de solos, o talude no seu processo de regeneração natural, iniciado pelo controle da erosão por meio do retaludamento, apresentou um total de 32 indivíduos de 22 espécies diferentes, distribuídas em 10 famílias botânicas com maior representação daquelas de hábito herbáceo, seguido por espécies arbustivas (Tabela 1).

Tabela 1. Distribuição das espécies amostradas e seu hábito.

\begin{tabular}{llll}
\hline Família/Espécie & Hábito & Família/Espécie & Hábito \\
\hline Angiosperma & & Mimosa pigra L. & Arbusto \\
Não identificada sp1 & Erva & Euphorbiaceae & - \\
Não identificada sp2 & Erva & Croton heliotropiifolius Kunth & Arbusto \\
Não identificada sp3 & Arbusto & Croton hirtus & Erva \\
Não identificada sp4 & Arbusto & Croton sp. & Erva \\
Não identificada sp5 & Erva & Lamiaceae & - \\
Não identificada sp6 & Trepadeira & Hyptis sp. & Erva \\
Asteraceae & - & Não identificada sp8 & Arbusto \\
Não identificada sp7 & Erva & Solanaceae & - \\
Smallanthus sp. & Erva & Capsicum annuum & Arbusto \\
Commelinaceae & - & Rhamnaceae & - \\
Commelina benghalensis & Erva & Ziziphus sp. & Arbusto \\
Cucurbitaceae & - & Rubiaceae & - \\
Momordica charantia & Trepadeira & Psychotria sp. & Erva \\
Fabaceae & - & Pteridófitas & - \\
Ingá sp. 1 & Arbórea & Lygodiaceae & - \\
Ingá sp. 2 & Arbórea & Lygodium venustum & Trepadeira \\
\hline
\end{tabular}

Essa variação estrutural e de composição se deve a alta frequência de alterações que ocorrem na vegetação de mata ciliar por conta dos processos erosivos, assim como a fácil colonização de novas áreas, devido a fisionomia das espécies que garantem boas condições de luminosidade, se tornando um importante fator para sucessão ecológica
(Carvalho, 2020). Jesus et al. (2020), analisando a estabilização de plantas de hábito arbóreo em área de mata ciliar do Rio Piauitinga, em Sergipe, observou que, durante a fase inicial de 90 dias, os fatores ambientais característicos da mata ciliar, podem influenciar positivamente na estabilização das espécies implantadas 
independente das sementes receberem tratamento para na superação da fase inicial.

Analisando os resultados dos parâmetros fitossociológicos da estrutura horizontal (Tabela 2), percebe-se que as espécies com maiores valores de Taxa de Cobertura Linear, Densidade Relativa, Taxa de
Cobertura Relativa e Índice Valor de Importância foram Mimosa pigra L. da família Fabaceae com valores de 42,47; 0,25; 56,03 e 56,28 respectivamente e a espécie Croton heliotropiifolius Kunth da família Euphorbiaceae com valores de 5,79; 0,09; 7,69 e 7,73 respectivamente.

Tabela 2. Distribuição das espécies identificadas e resultados da análise fitossociológica da estrutura horizontal. Taxa de Cobertura Linear (CL), Taxa de Cobertura Relativa (CR) Îndice Valor de Importância (IVI).

\begin{tabular}{|c|c|c|c|c|c|}
\hline Família/ espécie & $\mathbf{C L}$ & DR & $\mathbf{C R}$ & IVI & Status \\
\hline \multicolumn{6}{|l|}{ Angiosperma } \\
\hline Não identificada sp1 & 0,56 & 0,03 & 0,74 & 0,77 & - \\
\hline Não identificada sp2 & 0,84 & 0,03 & 1,10 & 1,14 & - \\
\hline Não identificada sp3 & 0,66 & 0,03 & 0,87 & 0,91 & - \\
\hline Não identificada sp4 & 3,24 & 0,03 & 4,28 & 4,31 & - \\
\hline Não identificada sp5 & 1,39 & 0,03 & 1,84 & 1,87 & - \\
\hline Não identificada sp6 & 0,42 & 0,03 & 0,55 & 0,58 & - \\
\hline Asteraceae & 3,70 & $\mathbf{0 , 6 0}$ & 4,88 & 4,94 & \\
\hline Não identificada sp7 & 0,56 & 0,03 & 0,74 & 0,77 & - \\
\hline Smallanthus sp. & 3,14 & 0,03 & 4,14 & 4,17 & - \\
\hline Commelinaceae & 1,15 & $\mathbf{0 , 0 3}$ & $\mathbf{0 , 5 5}$ & $\mathbf{0 , 5 8}$ & \\
\hline Commelinabenghalensis & 0,42 & 0,03 & 0,55 & 0,58 & Naturalizada \\
\hline Cucurbitaceae & 1,15 & $\mathbf{0 , 0 3}$ & 1,52 & $\mathbf{1 , 5 5}$ & \\
\hline Momordica charantia & 1,15 & 0,03 & 1,52 & 1,55 & Naturalizada \\
\hline Fabaceae & 44,84 & $\mathbf{0 , 3 1}$ & 59,15 & 56,28 & \\
\hline Ingá sp. 1 & 0,66 & 0,03 & 0,87 & 0,91 & - \\
\hline Ingá sp. 2 & 1,71 & 0,03 & 2,25 & 2,29 & - \\
\hline Mimosa pigra $L$. & 42,47 & 0,25 & 56,03 & 56,28 & Nativa \\
\hline Euphorbiaceae & 8,93 & 0,15 & 11,78 & 11,93 & \\
\hline Croton heliotropiifolius Kunth & 5,79 & 0,09 & 7,64 & 7,73 & Nativa \\
\hline Croton hirtus & 1,05 & 0,03 & 1,38 & 1,41 & Nativa \\
\hline Croton sp. & 3,00 & 0,03 & 3,96 & 3,99 & - \\
\hline Lamiaceae & 5,5 & 0,09 & 7,27 & 7,36 & \\
\hline Hyptis sp. & 1,32 & 0,03 & 1,75 & 1,78 & - \\
\hline Não identificada sp8 & 4,18 & 0,06 & 5,52 & 5,58 & - \\
\hline Rhamnaceae & $\mathbf{0 , 5 9}$ & $\mathbf{0 , 0 3}$ & $\mathbf{0 , 7 8}$ & $\mathbf{0 , 8 1}$ & \\
\hline Ziziphus sp. & 0,59 & 0,03 & 0,78 & 0,81 & - \\
\hline Rubiaceae & $\mathbf{0 , 6 3}$ & $\mathbf{0 , 0 3}$ & $\mathbf{0 , 8 3}$ & $\mathbf{0 , 8 6}$ & \\
\hline Psychotria sp. & 0,63 & 0,03 & 0,83 & 0,86 & - \\
\hline Solanaceae & 1,43 & $\mathbf{0 , 0 3}$ & 1,89 & 1,92 & \\
\hline Capsicum annuum & 1,43 & 0,03 & 1,89 & 1,92 & Naturalizada \\
\hline \multicolumn{6}{|l|}{ Pteridófitas } \\
\hline Lygodiaceae & $\mathbf{0 , 5 9}$ & $\mathbf{0 , 0 3}$ & $\mathbf{0 , 7 8}$ & $\mathbf{0 , 8 1}$ & \\
\hline Lygodium venustum & 0,59 & 0,03 & 0,78 & 0,81 & Nativa \\
\hline Total & $75,80 \%$ & 1,00 & 100 & 101 & \\
\hline
\end{tabular}


A espécie Mimosa pigra L. é um arbusto de raiz pivotante de ampla distribuição, ocorrendo na biorregião do neotrópico (bioregião que compreende América do sul e América central) e África. Essa espécie é comumente infestante de pastagens, áreas desocupadas e margens de rios ou lagos. É conhecida por formações densas que impedem $o$ acesso de animais a água, não diferente do que ocorreu na área de estudo deste trabalho, visto que essa espécie ocupa cerca de $43 \%$ da linha amostrada (Tabela 2) e possui o maior IVI do estudo (Heard et al., 2012; Silva, 2017).

Em um trabalho com estacas arbóreas/arbustivas, também no Baixo São Francisco, Gois (2014), constatou que a espécie Mimosa pigra L. possui potencial biotécnico para uso em obras de bioengenharia de solos, visto que apresentou estacas com rápida $\mathrm{e}$ vigorosa brotação e enraizamento para uso em biotécnicas do tipo manta de arbustos, além de rápido desenvolvimento com sistema radicular profundo, com potencial para atravessar o que é conhecido em um talude como superfície de ruptura, zona que o instabiliza para movimentos de massa de solo, provocando deslizamentos. Uma vez atravessada a superfície de ruptura, a raiz "grampeia" o solo, trazendo maior coesão e assim aumentando a resistência ao seu cisalhamento.

A família Euphorbiaceae apresenta alta diversidade de espécies e diferenças de hábitos garantindo maior capacidade de adaptação a variações do ambiente, como a formação vegetal que traz uma estrutura rala e de baixo porte (Li et al, 2019; Radcliffe-Smith, 2018). A espécie Croton heliotropiifolius Kunth também foi reportada em outros estudos de levantamento florístico e fitossociológico em outros estados do nordeste brasileiro (Dario, 2017).

Foi observada a ausência de espécies exóticas em toda a área do enrocamento vegetado, sendo considerado um resultado positivo, visto que invasão intensa de espécies exóticas, em geral, por serem agressivas e de grande capacidade de proliferação, trazem diversos impactos para o ecossistema, principalmente em se tratando de uma Área de Preservação Permanente (APP), como a zona ripária (Valone \& Weyers, 2019). É estabelecido que a bioinvasão em uma comunidade vegetal causa impactos na abundância e diversidade de espécies, afetando os processos ecológicos e ecossistêmicos, pois as espécies invasoras ocupam nichos e competem com as espécies nativas que já estão ali adaptadas (Souza, 2018).

As funções hidrológicas da cobertura vegetal na zona ripária consistem na redução do escoamento direto e evapotranspiração que influencia no aumento da vazão após uma chuva. A água infiltrada contribui para recarga de aquíferos e também para uma vazão contínua do sistema hídrico na estação seca, e a vegetação auxilia na qualidade desta água por meio da filtragem de nutrientes e sedimentos e a interação direta com o ecossistema aquático, como processos de deposição de sedimentos (Batista et al., 2018; Guimarães, 2019; Ramos e Rosini, 2018). Vale destacar a importância de uma densa cobertura relativa (CR) alcançando pelo menos $75,80 \%$ para que exista um efetivo controle da erosão, e contribuindo para o aumento da Taxa de infiltração com contribuição do sistema radicular.

\section{Banco de Sementes}

Na extensão do enrocamento vegetado nos dois ambientes formados, Vegetação Cerrada (VC) e Vegetação Menos Densa (VMD), foi observada a importância da recuperação do talude pela técnica de bioengenharia de solos, visto que não houve diferença na taxa de germinação das sementes proveniente das duas áreas.

Não foi observada diferença significativa ( $p$ value $>0,05)$ para o tamanho das plântulas $(p=1,3)$ e para velocidade de germinação $(p=0,49)$ do material submetido aos testes de germinação. No tratamento $\mathrm{VC}$, os dados iniciais apresentaram valores menores em comparação com o tratamento VMD (Figura 3). Entretanto, para tamanho das plântulas emergidas, a Vegetação cerrada apresentou valores maiores (Tabela 3).

Os valores para Velocidade de Germinação - VG se mantiveram constantes até o $12^{\circ}$ dia. Após isso, os valores para VG aumentaram significativamente. Na condução do ensaio ocorreu desligamento involuntário da BOD, por falta de energia no laboratório, criando uma condição diferente que evoluiu 
para a maior germinação das sementes e emergência das plântulas.

Tabela 3. Tamanho das plântulas emergidas.

\begin{tabular}{lcccc}
\hline \multicolumn{1}{c}{ Tratamento/Dias } & $\mathbf{5}$ & $\mathbf{8}$ & $\mathbf{1 2}$ & $\mathbf{1 5}$ \\
\hline Vegetação Menos Densa & 2,30 & 0,00 & 0,00 & 1,10 \\
Vegetação cerrada & 3,20 & 1,90 & 2,20 & 0,40 \\
& & & & \\
\hline
\end{tabular}

A Figura 4 mostra que a taxa de germinação se apresentou como um valor crescente para as duas áreas comparadas, podendo ser associada a um avanço positivo no processo de recuperação, devido à proteção do solo possibilitada pela vegetação (Santos et al., 2017). Ocorre que o menor arraste de partículas pelo menor deflúvio superficial por conta de uma maior infiltração da água, considerando também maior aporte de matéria orgânica que melhor estruturou o solo, mineralizando o carbono orgânico em nutrientes para as plantas, levando a uma melhor nutrição das plantas, consequentemente melhor florescimento e aumento na quantidade de sementes (Ferreira et al., 2019; Guimarães et al., 2019).

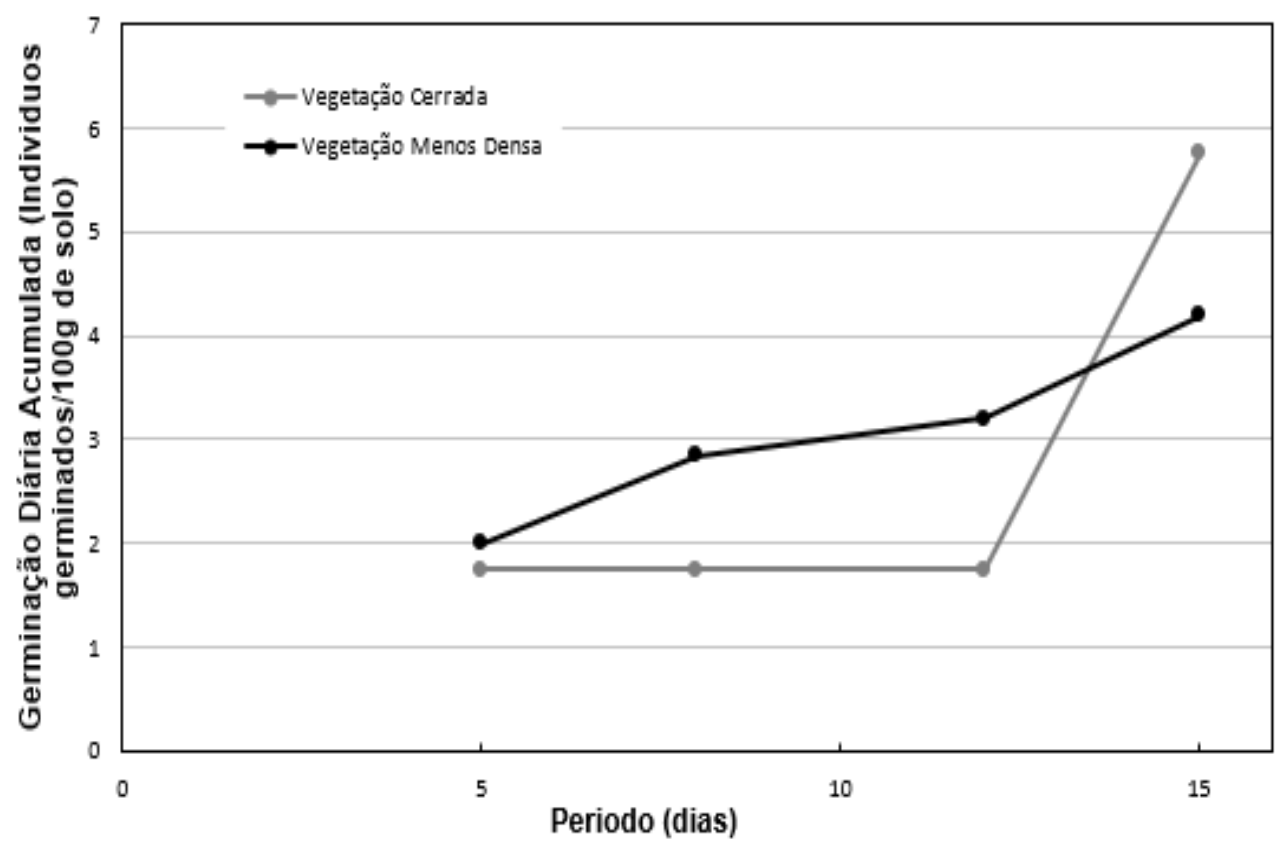

Figura 3. Taxa de germinação diária acumulada para cada 100 g de solo pelo período do experimento.

Com o propósito de estudar o comportamento germinativo da espécie aroeira (Myracrodruon urundeuva Allemão), Silva et al. (2019), destaca que o requerimento de luz para germinação está ligado à temperatura ótima demandada pela espécie, visto que eram sementes com fotoblastismo negativo. Para este trabalho, como havia o desconhecimento sobre a identificação das sementes, não foi possível a determinação do fotoblastismo para o teste de taxa de germinação.

\section{Resistência à Penetração}

Foi avaliada a Resistência à penetração (RP) e umidade do solo no enrocamento 
vegetado, e em ambiente diferente (controle) que apresentaram resultados significativamente diferentes ( $p$ value $<0,05$ ), ou seja, menor resistência à penetração no enrocamento vegetado quando comparado ao tratamento controle $(p=0,001$ e $\mathrm{p}=0,009$ respectivamente). $\mathrm{O}$ tratamento controle faz referência à uma área associada, ainda na zona ripária, onde não foram implantadas as técnicas de bioengenharia de solos.

O maior valor de RP para o tratamento com a biotécnica (enrocamento vegetado) foi de 6,59 Mpa na profundidade de 24-26 cm e o menor foi de 0,55 Mpa nos primeiros $4 \mathrm{~cm}$ de profundidade, diferentemente do tratamento controle que obteve o maior valor de 25,20 Mpa e o menor de 3,62 Mpa nas profundidades 62$64 \mathrm{~cm}$ e $0-2 \mathrm{~cm}$, respectivamente (Figura
4). Esses resultados repercutem a importância da vegetação na estruturação do solo, inclusive aumento da sua macroporosidade responsável pela drenagem interna do solo. A menor RP nas camadas mais superficiais do solo reflete possivelmente maior densidade radicular, que promove uma melhor estruturação do solo, concordando com Machado et al. (2018).

Percebe-se uma variação de RP aos 10 $\mathrm{cm}$ de profundidade, não ocorrendo diferenças significativas até $40 \mathrm{~cm}$, onde ocorre uma maior variação entre os tratamentos. Esse resultado provavelmente se deve ao tipo de solo da região (NEOSSOLO flúvico) que nas camadas mais arenosas encontra menor resistência do penetrômetro, e quanto mais argilosa é a textura do solo, maior a resistência a penetração (Bayat \& Zadeh, 2018; Silva, 2018).

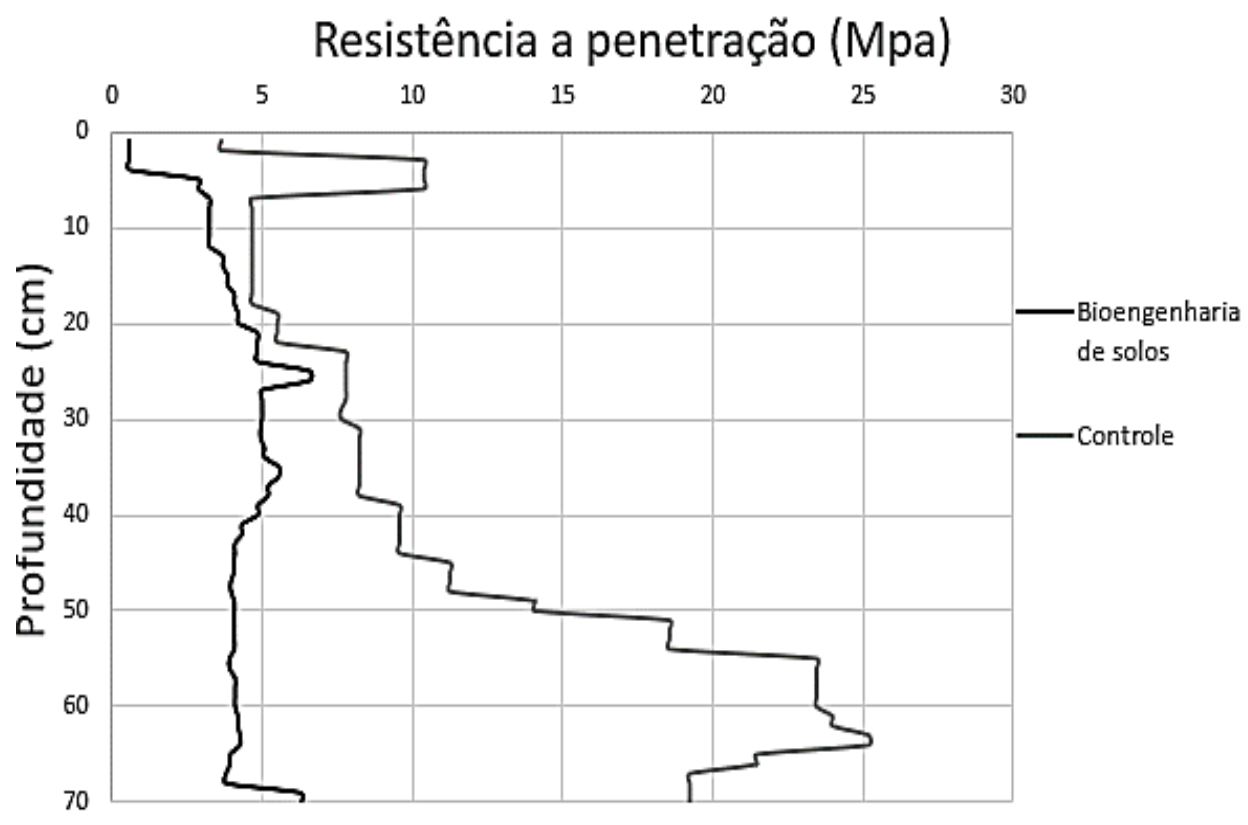

Figura 4. Resistência a penetração em profundidade, nos tratamentos com a técnica de bioengenharia de solos e na área controle.

Nos primeiros $10 \mathrm{~cm}$ de profundidade $\mathrm{o}$ tratamento com bioengenharia de solos não ultrapassou o valor de 3,50 Mpa. Embora esse valor traga dificuldades para penetração das raízes das plantas pois está acima do valor crítico (2,0 Mpa) (Rossetti \& Centurion, 2017), se mostra ainda viável para desenvolvimento do tipo de raiz das espécies observadas, e muito a baixo do valor observado quando comparado ao tratamento controle $10 \mathrm{Mpa}$.

A resistência do solo é o fator que mais influência no crescimento radicular, pois as raízes da vegetação tentam encontrar caminhos de baixa resistência para sua penetração durante seu crescimento. O melhor desenvolvimento radicular favorece a recuperação do talude 
através do seu reforço mecânico proporcionando uma maior força de coesão e resistência ao cisalhamento do solo. Com isso, RP se mostra um importante indicador para estabilização de taludes (Holanda et al., 2005; Nascimento \& Larios, 2020).

O conteúdo de umidade observado no tratamento com bioengenharia de solos foi de $18,64 \%$, e no tratamento controle foi de $6,21 \%$, concordando com os achados de Machado et al. (2018), quando afirmam que a RP é inversamente proporcional à umidade. $\mathrm{O}$ resultado apresentado se explica pelo acréscimo da matéria orgânica, que devido à presença da vegetação facilita a infiltração de água no solo e diminui a resistência à penetração, consequentemente aumentando a drenagem interna no perfil do solo, diminuindo a ocorrência de erosão. Almeida et al. (2018) pesquisando em Neossolo Flúvico destaca que a resistência do solo à penetração apresentou dependência espacial para todas as camadas da área estudada.
De acordo com os parâmetros técnicos da Soil Survey Staff (1993) a Resistência a Penetração (RP) no tratamento com bioengenharia de solos é caracterizada ainda como Muito Alta $(4,0-8,0)$ enquanto o tratamento controle, sem a presença de biotécnica pode ser identificada como Extremamente Alta $(>8,0)$.

Velocidade de Infiltração Básica (VIB)

Na Figura 5 observa-se que a taxa de infiltração no início do teste apresenta grande variação de VIB e logo após, tende a um valor constante. Essa variação pode ser explicada por fatores como a carga hidráulica, ou seja, a espessura da lâmina de água que atua como uma força para infiltração, assim como explicada pela umidade inicial do solo e o tipo de solo em que foi realizado o teste.

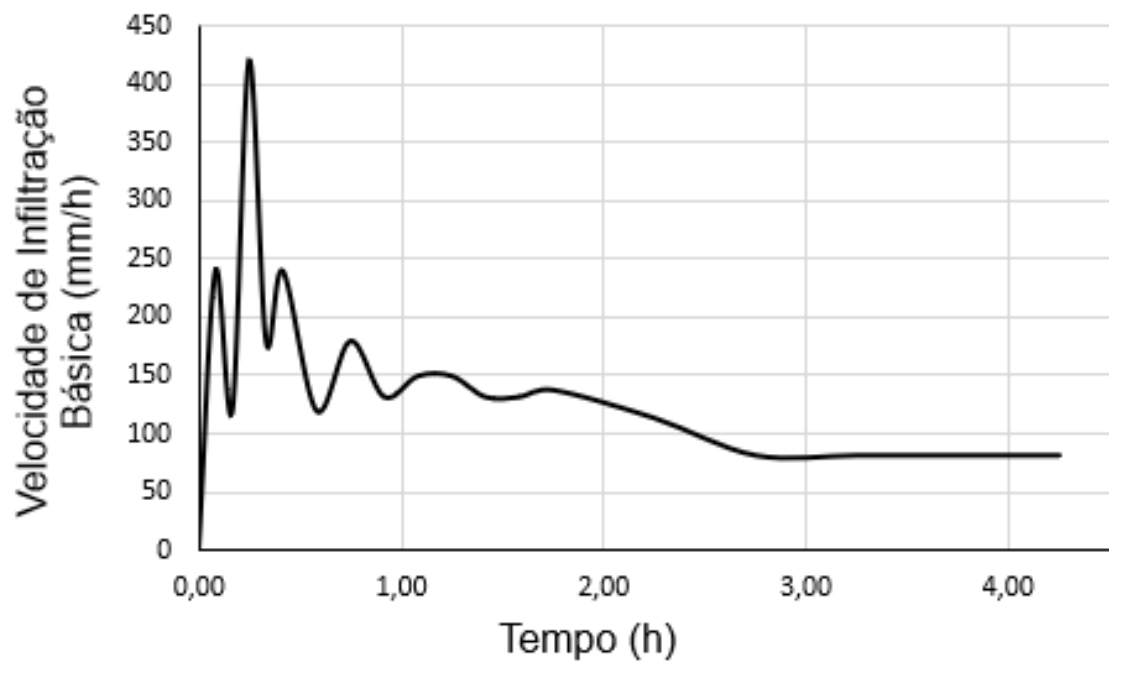

Figura 5. Velocidade de Infiltração Básica (VIB) da área com bioengenharia de solos. Fontes: Os Autores.

A VIB do solo amostrado foi de $164 \mathrm{~mm} / \mathrm{h}$ sendo classificada como muito alta (VIB > 30 mm.h-1) que concordando com Pinheiro et al. (2018), pode ser explicada pela influência da cobertura vegetal na infiltração. A presença do sistema radicular das plantas possibilita caminhos preferenciais, facilitando a entrada de água no solo. Caminhos esses que podem surgir também pela atividade microbiana que decompõe a matéria orgânica existente em decorrência da cobertura vegetal. Vale ressaltar que a vegetação contribui para redução da velocidade de escoamento superficial (Domingues et al., 2018).

A velocidade de infiltração reflete os importantes processos ecossistêmicos como a retenção de água utilizada posteriormente pelas 
plantas e está atrelado também ao escoamento superficial da água no solo, e que pode também, ser ligada a resistência à penetração do solo (Martins \& Santos, 2017). Solos com alta resistência à penetração possuem maior grau de compactação e consequentemente maior escoamento superficial que se reflete em significativa diminuição da infiltração (Souza et al., 2020; Rangel, 2018).

Este trabalho buscou avaliar a recuperação hidroambiental visando controle efetivo da erosão na margem de um grande rio, aliado ao processo de recuperação ecológica, por meio de definição de metodologia para o monitoramento de ações resultantes de bioengenharia de solos.

Com a metodologia empregada fundamentada nas biotécnicas, foi possível identificar precisamente a contribuição da vegetação ripária, que auxilia na contenção de taludes, uma vez que a cobertura vegetal protege a superfície do solo contra ações erosivas como o vento e a água da chuva. As raízes por sua vez apresentam contribuição no reforço mecânico contra cisalhamento do solo, e o banco de sementes atua na renovação da regeneração natural resultando na resiliência ecossistêmica para o ambiente.

\section{Conclusões}

A regeneração natural ou recuperação florística do talude da margem do rio São Francisco se mostrou eficiente e comprovada pelo aumento exponencial do número de espécies desde a sua implantação, que evoluiu de somente duas espécies, e alcançou o numero de 22 espécies diferentes, distribuídas em 10 famílias botânicas, no período de 2011 a 1019.

A análise da fitossociologia e projeção horizontal da comunidade vegetal como indicador para regeneração natural se mostrou eficiente dada a importância da cobertura vegetal em áreas de recuperação florística natural.

Os atributos físicos do solo representados pela Resistência a Penetração (RP) e Velocidade e Infiltração Básica (VIB) se mostraram parâmetros muito importantes para uma avaliação do equilíbrio estrutural e de estabilidade ecossistêmica do talude recuperado, uma vez que testemunharam a importância da vegetação na recuperação do solo e consequente melhor estruturação, que repercute numa melhoria na infiltração de água no solo, melhor conservação do solo e da água e consequentemente menor vulnerabilidade do talude à erosão.

A metodologia trabalhada para avaliação da recuperação hidroambiental da margem do rio São Francisco, se apresentou bem ajustada aos objetivos uma vez que contemplou parâmetros essenciais para a compreensão integrada do ambiente, servindo como base para programas de monitoramento em obras que se utilizam de técnicas de bioengenharia de solos.

\section{Referências}

Almeida, A. N. de, Lara, C. L. de, \& Angelo, H. (2019). Avaliação do custo para recuperar uma área degradada: Estudo de caso em uma área de preservação permanente do Rio Bisnau (Formosa, Estado de Goiás, Brasil). Revista Brasileira de Gestao Ambiental e Sustentabilidade, 6(13), 349364.

Almeida, R. F. B., Lagos, M. do C. C., \& de Castro, S. S. (2018). Avaliação físico-química de uma topossequência com neossolos quartzarênicos para fins de conservação, Mineiros, GO. Revista de Ciências Ambientais, 12(3), 35-49.

Araújo Filho, R. N. de, Holanda, F. S. R., Pedrotti, A., de Oliveira Santos, T., \& da Rocha, I. P. (2017). Influência dos atributos físicos-mecânicos do solo na estabilidade do talude do Baixo São Francisco. Scientia Agraria, 18(4), 107-113.

Arthur, J. L., Murray, G., Rollins, R., Dearden, P., \& Stahl, A. (2020). Differential impacts of dam construction on livelihoods in Ghana. African Geographical Review. Scopus. doi: 10.1080/19376812.2020.1719367

Bandeira, A. A., Holanda, F. S. R., Casado, A. P. B., \& Araújo Filho, R. N. de. (2012). Influência do fluxo e refluxo do aquífero na evolução do processo erosivo na margem do rio São Francisco.

Batista, L. V., Santarosa, L. V., dos Santos, V., \& Gastmans, D. (2018). Influência das águas subterrâneas na manutenção da vazão do rio em área de recarga do sistema Aquífero Guarani. Águas Subterrâneas.

Bayat, H., \& Zadeh, G. E. (2018). Estimation of the soil water retention curve using penetration resistance curve models. Computers and Electronics in Agriculture, 144, 329-343. doi: 10.1016/j.compag.2017.10.015

Bernardo, S., Mantovani, E. C., \& Soares, A. A. (2008). Manual de Irrigação (p. 611). Viçosa, UFV. 
Canfield, R. Hi. (1941). Application of the line interception method in sampling range vegetation. Journal of forestry, 39(4), 388-394.

Canfield, Roy Hyer. (1950). Sampling ranges by the line interception method. Recuperado de https://agris.fao.org/agrissearch/search.do?recordID=US201300128117

Carvalho, A. M., Santos, L. D. V., Holanda, F. S. R., Pedrotti, A., \& Antonio, G. M. (2020). Digital image processing for evaluation of Paspalum millegrana schrad root. Revista Caatinga, 33(01), 100-107.

Carvalho, D. N. (2020). Efeito da Restauração Ecológica na Recuperação e Conservação da Avifauna em Fragmentos de Mata Ciliar no Rio Uberabinha, em Uberlândia, MG. doi: http://doi.org/10.14393/ufu.di.2019.2597

Dario, F. R. (2017). Estudo fitossociólgico de uma área de caatinga em estágio inicial de sucessão ecológica no estado da Paraíba, Brasil. Revista Geotemas, 7(1), 71-83. doi: 10.33237/geotemas.v7i1.2581

Domingues, G. F. (2018). Otimização de zonas de vegetação para minimizar a perda de solos em bacias hidrográficas. Tese (Doutorado em Ciência Florestal) - Universidade Federal de Viçosa, 2018.

Emadi-Tafti, M., Ataie-Ashtiani, B., \& Hosseini, S. M. (2021). Integrated impacts of vegetation and soil type on slope stability: A case study of Kheyrud Forest, Iran. Ecological Modelling, 446, 109498.

Ferreira, N. C. de F., Duarte, J. R. de M., Oliveira, L. A. B., Silva, E. C., \& Carvalho, I. A. (2019). O papel das matas ciliares na conservação do solo e água. Biodiversidade, 18(3), 171-180.

Gois, S. S. (2014). Recomposição da floresta ripária na margem do Rio São Francisco.

Gu, Z., Fan, H., \& Wang, Y. (2020). Dynamic characteristics of sandbar evolution in the lower Lancang-Mekong River between 1993 and 2012 in the context of hydropower development. Estuarine, Coastal and Shelf Science, 237. Scopus. doi: 10.1016/j.ecss.2020.106678

Guimarães, L. M., Lima, T. de A. C., França, E. J. D., Arruda, G. N. de, Souza, J. R. B. de, AlbergariaBarbosa, A. C. R. de, ... Albergaria-Barbosa, A. C. R. de. (2019). Impacts of local vegetation changes in the organic matters input for a preserved tropical estuary (Itapicuru-BA River Estuary). Química Nova, 42(6), 611-618. doi: 10.21577/01004042.20170370

Guimarães, R. Z. (2019). Avaliação da qualidade de água no processo de recuperação de áreas de plantio de Pinus taeda em APP na bacia do Rio Campinas-Joinville-SC.

Hara, J., Atique, U., \& An, K.-G. (2020). Multiyear links between water chemistry, algal chlorophyll, drought-flood regime, and nutrient enrichment in a morphologically complex reservoir. International Journal of Environmental Research and Public Health, 17(9). Scopus. doi: 10.3390/ijerph17093139

Heard, T. A., Mira, A., Fichera, G., \& Segura, R. (2012). Nesaecrepida infuscata: A biological control agent of the invasive plant Mimosa pigra. BioControl, 57(4), 573-580.

Hilary, B., Chris, B., North, B. E., Maria, A. Z. A., Lucia, A. Z. S., Alberto, Q. G. C., \& Andrew, W. (2021). Riparian buffer length is more influential than width on river water quality: A case study in southern Costa Rica. Journal of Environmental Management, 286, 112132.

Holanda, F. S. R. (2000). Estudo integrado do vale do São Francisco sergipano: Região de tabuleiros costeiros e pediplano sertanejo-pedologia. Aracaju: CODEVASF.

Holanda, F. S. R., Santos, L. da C. G., Araujo Filho, R. N., Pedrotti, A., Gomes, L. J., \& Conceição, F. G. (2011). Percepção dos ribeirinhos sobre a erosão marginal e a retirada da mata ciliar do Rio São Francisco no seu baixo curso.

Holanda, F. S. R., Santos, L. G. da C., Santos, C. M. dos, Casado, A. P. B., Pedrotti, A., \& Ribeiro, G. T. (2005). Riparian vegetation affected by bank erosion in the Lower São Francisco River, Northeastern Brazil. Revista Árvore, 29(2), 327336. doi: 10.1590/S0100-67622005000200016

Holanda, F. S. R., Wanderley, L. de L., Mendonça, B. de S., Santos, L. D. V., Rocha, I. P. da, \& Pedrotti, A. (2020). Formação de ondas e os processos erosivos nas margens do lago da UHE Xingó. Revista Brasileira de Geografia Física, 13(2), 887902. doi: 10.26848/rbgf.v13.2.p887-902

Irving, G. J., Round, P. D., Savini, T., Lynam, A. J., \& Gale, G. A. (2018). Collapse of a tropical forest bird assemblage surrounding a hydroelectric reservoir. Global Ecology and Conservation, 16. Scopus. doi: 10.1016/j.gecco.2018.e00472

Jesus, J. B. de, Ferreira, R. A., Gama, D. C., \& Oliveira, A. M. S. de. (2020). Sobrevivência de plântulas de espécies florestais nativas, em mata ciliar no estado de Sergipe. Pesquisa Florestal Brasileira, 40(0). doi: 10.4336/2020.pfb.40e201801734

Jiang, H., Simonovic, S. P., Yu, Z., \& Wang, W. (2020). A system dynamics simulation approach for environmentally friendly operation of a reservoir system. Journal of Hydrology, 587. Scopus. doi: 10.1016/j.jhydrol.2020.124971

Koppa, A., Gebremichael, M., Zambon, R. C., Yeh, W. W. G., \& Hopson, T. M. (2019). Seasonal Hydropower Planning for Data-Scarce Regions Using Multimodel Ensemble Forecasts, Remote Sensing Data, and Stochastic Programming. Water 
Resources Research, 55(11), 8583-8607. Scopus. doi: 10.1029/2019WR025228

Li, J., Gao, X., Sang, S., \& Liu, C. (2019). Genomewide identification, phylogeny, and expression analysis of the SBP-box gene family in Euphorbiaceae. BMC genomics, 20(9), 912.

Machado, L., Holanda, F. S. R., Pedrotti, A., Ferreira, O. J. M., Araújo Filho, R. N. de, \& Moura, M. M. (2018). Effect of vetiver roots on soil resistance to penetration in a typic fluvic neossol in the São Francisco riverbank. Revista Caatinga, 31(4), 935943.

Machado, L., Holanda, F. S. R., Pedrotti, A., Ferreira, O. J. M., de Araújo Filho, R. N., \& Moura, M. M. (2018). Efeito de raízes de vetiver sobre a resistência à penetração de um neossolo flúvico nas margens do rio São Francisco. Revista Caatinga, 31(4), 935-943.

Maffra, C. R. B., \& Sutili, F. J. (2020). The use of soil bioengineering to overcome erosion problems in a pipeline river crossing in South America. Innovative Infrastructure Solutions, 5(1), 24. doi: 10.1007/s41062-020-0273-5

Martins, F. P., \& dos Santos, E. L. (2017). Taxa de infiltração da água e a resistência do solo a penetração sob sistemas de uso e manejo. Acta Iguazu, 6(4), 28-40.

Medinas de Campos, M., Tritico, H. M., Girard, P., Zeilhofer, P., Hamilton, S. K., \& Fantin-Cruz, I. (2020). Predicted impacts of proposed hydroelectric facilities on fish migration routes upstream from the Pantanal wetland (Brazil). River Research and Applications, 36(3), 452-464. Scopus. doi: 10.1002/rra.3588

Moura, M. M., dos Santos Fontes, C., dos Santos, M. H., de Araujo Filho, R. N., \& Holanda, F. S. R. (2017). Estimativa de perda de solo no Baixo São Francisco sergipano. Scientia Agraria, 18(2), 126135.

Naresi, R. J., Paiva, J., Accioli, L., \& Targa, M. S. (2017). Projeção do escoamento superficial, classes de uso e taxas de ocupação do solo no período de 2003 a 2033 na bacia Ribeirão Pouso Frio. 1(1). Recuperado de http://www.agro.unitau.br/repositorio/index.php/r $\mathrm{ca} /$ article/view/6

Nascimento, C. A. do, \& Larios, M. R. B. (2020). Cartas geotécnicas: Desenvolvimento de software gerador de perfil de resistência à penetração do subsolo do UNASP-EC. Caminhos de Geografia, 21(73), 321-331-321-331.

Nascimento, J. G. C. (2009). A influência da erosão na regeneração de clareiras.

Obriejetan, M., Stangl, R., \& Innerhofer, G. (2017). Revetment restoration of sealed hydroelectric storage and compensating reservoirs.Procedia Environmental Science, Engineering and
Management, 4(4), 265-272. Scopus. Recuperado de Scopus.

Parhizkar, M., Shabanpour, M., Miralles, I., Cerdà, A., Tanaka, N., Asadi, H., \& Zema, D. A. (2021). Evaluating the effects of forest tree species on rill detachment capacity in a semi-arid environment. Ecological Engineering, 161, 106158.

Pinheiro, A. G., dos Santos, J. C. N., de Queiroz Palácio, H. A., de Araújo Neto, J. R., \& de Andrade, E. M. (2018). Eficiência da Cobertura Vegetal na Redução das Perdas de Água e Solo no Município de Iguatu. IRRIGA, 23(1), 133-142.

Radcliffe-Smith, A. (2018). A review of the family Euphorbiaceae. In Naturally Occurring Phorbol Esters (p. 63-85). CRC Press.

Ramos, C. I., \& Rosini, E. F. (2018). Macroinvertebrados bentônicos como bioindicadores da qualidade da água da bacia hidrográfica popuca-botinhas, Guarulhos (SP). Revista Saúde-UNG-Ser, 11(2 ESP), 13.

Rangel, L. A., \& Guerra, A. J. T. (2018). Microtopografia e compactação do solo em trilhas geoturísticas no litoral do Parque Nacional da Serra da Bocaina-estado do Rio de Janeiro. Revista Brasileira de Geomorfologia, 19(2).

Reichert, J. M., Suzuki, L., \& Reinert, D. J. (2007). Compactação do solo em sistemas agropecuários e florestais: Identificação, efeitos, limites críticos e mitigação. Tópicos em ciência do solo, 5, 49-134.

Rey, F., Bifulco, C., Bischetti, G. B., Bourrier, F., De Cesare, G., Florineth, F., ... Phillips, C. (2019). Soil and water bioengineering: Practice and research needs for reconciling natural hazard control and ecological restoration. Science of the total environment, 648, 1210-1218.

Rosa, V., \& Gaiofatto, R. L. (2019). Bioengenery applied to slopes stabilization in Petrópolisrj/bioengenharia aplicada à estabilização de encostas no município de Petrópolis-rj. Revista de Engenharia da Universidade Católica de Petrópolis, 12(1), 1-15.

Santana, I.D.M. ; Holanda, F.S.R. ; Araujo Filho, R. N. (2012). Potencial biotécnico das espécies Aroeira Schinus terebinthifolius Raddi e Sabiá Mimosa caesalpiniaefolia Benth para recuperação de taludes marginais no baixo São Francisco. SCIENTIA PLENA, 8, 1-4.

Santos, G. L. D., Pereira, M. G., Conto, T. D., Carvalho, D. C. D., Amorim, T. A. D., Mendonça, V. M. M., \& Moraes, L. F. D. D. (2017). Influência da pedoforma na composição do banco de sementes em floresta secundária na região de Mar de Morros, Pinheiral-RJ. Ciência Florestal, 27(4), 1217-1228.

Silva, E. M., Pereira, J. C., Ferreira, V. M., \& Souza, R. C. (2019). Germination of Stigmaphyllon 
blanchetii Seeds in Different Temperatures and Luminosity. Planta Daninha, 37.

Silva, J. A., Almeida, S. C., Amorim, M. C., Wanderley, J. V., \& Amaral, L. G. (2019). Infiltração da água no solo e resistência à penetração em diferentes sistemas de cultivo na região Oeste da Bahia. Pesquisare-A Revista Eletrônica da UFOB, 3(1), 104-104.

Silva, J. M. (2017). Revisão histórica da diversidade vegetal da Zona da Mata Norte de Pernambuco com ênfase no município de goiana. Revista Espaço Acadêmico, 16(191), 12-26.

Silva, J. R. (2018). Variabilidade espacial da resistência à penetração em solo cultivado com cana-de-açúcar sob colheita mecanizada com tráfego controlado.

Soares, N. da M., Ferreira, R. A., Vieira, H. dos S., Jesus, J. B. de, Oliveira, D. G. de, \& Silva, A. C. da C. (2019). Regeneração natural em área de Caatinga no Baixo São Francisco sergipano: Composição, diversidade, similaridade florística de espécies florestais. Advances in Forestry Science, 6(3), 711-716. doi: 10.34062/afs.v6i3.7563
Souza, A. P. S. L. (2018). Bioinvasão: Impacto potencial de espécies invasoras na zona costeira marinha.

Souza, J. F. D., Bonini, C. D. S. B., Mateus, G. P., de Souza, C. T., Perusso, R. L. S., Pedro, F. G., \& Oliverio, G. L. (2020). Compactação do solo em sistemas de integração lavoura-pecuáriafloresta após cinco anos de implantação e uso. Revista de Ciências Agroveterinárias, 19(3), 348-353.

SPSS Corp, R. 2017. (2017). IBM SPSS Statistics for Macintosh, Version 25.0 (Versão 24). Armonk, NY: IBM.

Vázquez, E., Benito, M., Espejo, R., \& Teutscherova, N. (2020). Response of soil properties and microbial indicators to land use change in an acid soil under Mediterranean conditions. CATENA, $189,104486$. 